\title{
Wage curve in dual labor markets: cross-sectional evidence from Japan
}

\author{
Kazuyuki Inagaki* \\ Graduate School of Economics, Nagoya City University, Japan
}

Received: 26 January 2015

Revised: 21 April 2015

Accepted: 22 April 2015

\begin{abstract}
Using a threshold regression model, we find that the wage-unemployment relationship in Japan depends on the degree of labor market duality. The unemployment elasticity of wages is negative for the group with a lower degree of duality and, therefore, the Japanese wage curve holds for that group. However, the wage-unemployment relationship is reversed if the share of non-regular workers exceeds approximately 30\%. Therefore, the Japanese wage curve does not hold for the group with a higher degree of duality, and alternative theories such as compensating differentials may be useful to explain this group.
\end{abstract}

Keywords: wage curve, dual labor market, threshold, non-regular workers

JEL Classification Codes: J30, R10

\section{Introduction}

The purpose of this paper is to examine the wage curve for Japan. The wage curve shows a negative relationship between wages and unemployment rates; this relationship is consistent with the bargaining and efficiency wage theories (Blanchflower and Oswald, 1994). For example, the bargaining theory suggests that high unemployment reduces the bargaining power of trade unions and prompts employees to accept lower wages. This relationship suggests that a worker who is employed in a region of high unemployment earns less than does an identical individual who works in a region of low unemployment. The slope coefficient of the wage curve can be interpreted as wage flexibility, which measures the sensitivity of wages to an excessive supply in a local labor market (Aixalá and Pelet, 2010).

Blanchflower and Oswald (1994) find that the unemployment elasticity of wages is -0.1 and is stable for many countries. Following Blanchflower and Oswald (1994), many studies have confirmed this relationship for more than 40 countries. ${ }^{1}$ However, little attention seems to have been paid to the impact of labor market duality on the wage curve. As the

\footnotetext{
*E-mail: inagaki@econ.nagoya-cu.ac.jp. and Business Letters, 4(2), 51-56.

${ }^{1}$ For details, see Blanchflower and Oswald (2005).

Citation: Inagaki, K. (2015) Wage curve in dual labor markets: cross-sectional evidence from Japan, Economics 
insider-outsider theory of the labor market suggests, unequal treatment of workers affects wages and unemployment. Therefore, the structure of the wage curve is likely to depend on the degree of labor market duality. ${ }^{2}$ To examine this impact, the use of Japanese data is helpful.

Labor market duality in Japan has increased dramatically in recent years (OECD, 2013). The share of non-regular workers has increased from $20 \%$ in 1994 to $35 \%$ in $2013 .{ }^{3}$ However, non-regular workers are confronted with several problems, such as lower wages, unstable employment, poor working conditions, and limited social insurance coverage. For example, the gap between the hourly wages of full-time and part-time workers is $31 \%$ for males and $48 \%$ for females. Similarly, about half of non-regular workers do not have social insurance coverage whereas almost all regular workers have the coverage. Furthermore, only $12.8 \%$ of non-regular workers spend more than ten years at the same firm, compared to $49.4 \%$ of regular workers, and this short tenure reduces their opportunities for job training. ${ }^{4}$ The unequal treatment of regular and non-regular workers is one of the important characteristics of the Japanese labor market.

Since bargaining power and employment protection in Japan are greater for regular workers than for non-regular workers (OECD, 2013), the wage-unemployment relationship for regular workers is likely to be explained by the theories behind the wage curve. However, the behavior of non-regular workers in Japan may not be well described by these theories, since these workers' conditions are much different from those of regular workers. In this respect, there is room for further investigation. Since labor market duality is also significant in several other developed countries, our empirical analysis may provide useful insights into the structure of labor markets in such countries.

\section{Methods}

In this paper, we consider the share of non-regular workers as the degree of labor market duality in Japan for the reasons mentioned in Section 1. The unemployment elasticity of wages is the main focus of the literature on the wage curve. To examine the impact of labor market duality on the Japanese wage curve, we use the threshold regression technique developed by Hansen (2000) and assume that the unemployment elasticity of wages depends on the share of non-regular workers. This assumption enables us to obtain information on the degree of labor market duality that significantly affects the structure of the Japanese wage curve.

We estimate the following model:

$$
\begin{array}{rl}
W_{a, r, s}=\alpha_{1} U_{a, r, s} & I\left(N_{a, r, s} \leq \gamma\right)+\beta_{1} U_{a, r, s} I\left(N_{a, r, s}>\gamma\right) \\
& +\alpha_{0} I\left(N_{a, r, s} \leq \gamma\right)+\beta_{0} I\left(N_{a, r, s}>\gamma\right)+\phi Z_{a, r, s}+\varphi X_{a, r, s}+\varepsilon_{a, r, s},
\end{array}
$$

where $W_{a, r, s}$ denotes the real hourly wages; $U_{a, r, s}$, the unemployment rate; $N_{a, r, s}$, the share of non-regular workers; $Z_{a, r, s}$, a vector of dummy variables; $X_{a, r, s}$, a vector of control variables; $\varepsilon_{a, r, s}$, an error term; and $\alpha_{1}, \alpha_{0}, \beta_{1}, \beta_{0}, \phi$, and $\varphi$, the coefficients to be

\footnotetext{
${ }^{2}$ Baltagi et al. (2012), Berg and Contreras (2004), and Ramos et al. (2010) are a few notable studies focusing on the wage curve for informal workers.

${ }^{3}$ In Japan, the number of non-regular workers is usually calculated by summing the number of part-time, temporary, dispatched, contract, entrusted, and other non-regular employees.

${ }^{4}$ For further details, see Jones and Urasawa (2011) and OECD (2013).
} 
estimated. The subscripts $a, r$, and $s$ represent age group, region, and sex, respectively. All variables are natural logarithms.

The indicator function $I\left(N_{a, r, s} \leq \gamma\right)$ takes the value of 1 for $N_{a, r, s} \leq \gamma$ and 0 otherwise, and $I\left(N_{a, r, s}>\gamma\right)=1-I\left(N_{a, r, s} \leq \gamma\right) . \gamma$ is the threshold parameter used to split the sample into two regimes. Therefore, the significance of the threshold effect in Eq. 1 produces two estimates of the unemployment elasticity of wages $\left(\alpha_{1}, \beta_{1}\right)$, depending on the degree of labor market duality. ${ }^{5}$

The dummy variables in Eq. 1 include age group, region, and sex. ${ }^{6}$ The control variables in Eq. 1 include educational attainment, length of service, the marriage rate, the share of professional and engineering workers, and the employment share of the primary sector. ${ }^{7}$ Following Hansen (1999), we assume that the coefficients on the control variables are the same for each of the two regimes.

Let $S_{n}(\gamma)$ be the sum of squared errors obtained from the ordinary least squares estimation of Eq. 1 conditional on $\gamma$. Then, $\hat{\gamma}$ is defined as

$$
\hat{\gamma}=\underset{\gamma}{\operatorname{argmin}} S_{n}(\gamma) .
$$

The observations of the threshold variable $N_{a, r, s}$ constitute the values of $\gamma$. Following Hansen (2000), we calculate the 95\% confidence interval of $\gamma$ from the likelihood ratio statistic and its critical value. We then compute the $p$-value for the null hypothesis of no threshold effect by using the bootstrap technique with 1,000 replications.

\section{Data}

As Deller (2011) points out, the literature on the wage curve can be classified into two groups: one group using individual-level data (e.g., Baltagi et al., 2009, 2012, 2013; Berg and Contreras, 2004; Ramos et al., 2010) and the other using aggregate data such as regional data (e.g., Deller, 2011; Shilov and Möller, 2009). We use aggregate data mainly because the data for individual regular and non-regular workers in Japan are not available for this study.

We obtain our cross-sectional data from the 2010 Japan Census and the 2010 Basic Survey on Wage Structure. ${ }^{8}$ Japan has 47 prefectures. In this study, we divide each prefecture into nine age groups $(20-24,25-30, \ldots, 60-64)$ and further divide them into males and females. Thus, the sample size is 846 .

Annual earnings are calculated by summing monthly contractual cash earnings multiplied by 12 and annual special cash earnings. Hours worked are calculated as the sum of scheduled hours and overtime hours worked. We use these data and the regional difference index of consumer prices to calculate real hourly wages. ${ }^{9}$ We calculate the unemployment rate by dividing the number of unemployed people by the total number of people in the labor force.

\footnotetext{
5 For other issues such as spatial and dynamic effects, see Baltagi et al. (2009, 2012) and Deller (2011).

${ }^{6}$ If these dummy variables are excluded from the threshold regression, the main results remain unchanged.

7 Further details are provided in Section 3.

${ }^{8}$ Panel data is very useful in wage curve studies. However, labor market duality in Japan has increased dramatically in recent years. Since the Japan Census is conducted every five years, the latest cross-sectional data seems most useful for this study.

${ }^{9}$ If we instead use data on real annual earnings, the following results are unchanged.
} 
We obtain the number of non-regular workers by summing the number of part-time, temporary, dispatched, and other non-regular employees; this is equal to the number of total employees minus the number of regular employees. Educational attainment is calculated as the share of workers whose educational level is higher than high school. Professional and engineering workers include individuals engaged in technical works, such as researchers, engineers, and medical doctors (Major Group B of the Japan Standard Occupational Classification), and we use the data for those workers whose highest educational level is college, university, or graduate school as a measure of highly skilled workers.

\section{Results}

As Table 1 shows, the point estimate of $\gamma$ is 0.305 , and the $95 \%$ confidence interval is very narrow. Furthermore, the null hypothesis of no threshold effect is rejected. Therefore, the structure of the Japanese wage curve depends on the degree of labor market duality.

Table 1. Test for threshold effect

\begin{tabular}{ccc}
\hline \hline (A) Threshold parameter $\gamma$ & & \\
\hline & Estimate & $95 \%$ confidence interval \\
\hline & 0.305 & {$[0.288,0.307]$}
\end{tabular}

(B) Test for threshold effect

\begin{tabular}{ccc}
\hline & Null hypothesis & Bootstrap $p$-value \\
\hline $\mathrm{H}_{0}: \alpha=\beta$ & 0.000 \\
\hline \hline
\end{tabular}

Note: $\alpha=\left(\alpha_{0}, \alpha_{1}\right)$ and $\beta=\left(\beta_{0}, \beta_{1}\right)$

Table 2 shows the estimation results of the Japanese wage curve with the threshold effect. ${ }^{10}$ The unemployment elasticity of wages is -0.038 for the regime in which $N_{a, r, s} \leq 0.305$, and 0.103 for the regime in which $N_{a, r, s}>0.305 .{ }^{11}$ The coefficients on the control variables have the expected signs.

The number of observations is 348 for the regime in which $N_{a, r, s} \leq 0.305$. This regime consists mainly of middle-aged males, and approximately $90 \%$ of them are regular workers. The Japanese wage curve holds for this regime. This result is consistent with the previous studies that use individual-level data for full-time workers (e.g., Baltagi et al., 2009, 2012).

However, the Japanese wage curve does not hold for the regime in which $N_{a, r, s}>0.305$, since the unemployment elasticity of wages is positive in this regime.

\footnotetext{
10 The estimation results of the coefficients on the dummy variables are not reported in this paper for space reasons but are available from the author upon request.

${ }^{11}$ To check for possible endogeneity in Eq. 1, we use the instrumental variable (IV) technique. Following Aixalá and Pelet (2010), we assume that the unemployment rate is an endogenous variable and use the lagged unemployment rate as an instrumental variable. Based on the same threshold effect as that reported in Table 1, the main results remain essentially unchanged. The IV estimation results are not reported in this paper but are available from the author upon request.
} 
Table 2. Estimation results of Eq. 1

\begin{tabular}{lcc}
\hline \hline Variable & Coefficient & Standard error \\
\hline$I\left(N_{a, r, s} \leq 0.305\right)$ & $-2.265^{* *}$ & {$[0.145]$} \\
$I\left(N_{a, r, s}>0.305\right)$ & $-2.668^{* *}$ & {$[0.145]$} \\
Unemployment rate $\times I\left(N_{a, r, s} \leq 0.305\right)$ & $-0.038^{*}$ & {$[0.016]$} \\
Unemployment rate $\times I\left(N_{a, r, s}>0.305\right)$ & $0.103^{* *}$ & {$[0.017]$} \\
& & \\
Educational attainment & $0.107^{* *}$ & {$[0.027]$} \\
Length of service & $0.368^{* *}$ & {$[0.024]$} \\
Marriage rate & $0.044^{*}$ & {$[0.021]$} \\
Share of professional and engineering workers & $0.027^{*}$ & {$[0.013]$} \\
Employment share of primary sector & $-0.025^{* *}$ & {$[0.008]$} \\
\hline \hline
\end{tabular}

Notes: The White heteroskedasticity consistent standard errors are reported. The results remain unchanged if we use the usual least squares standard errors. ** and * indicate significance at the $1 \%$ and $5 \%$ levels, respectively.

\section{Concluding remarks}

We find that the wage-unemployment relationship in Japan depends on the degree of labor market duality. The unemployment elasticity of wages is negative for the group with a lower degree of duality and, therefore, the Japanese wage curve holds for that group. Since this group consists mainly of regular workers whose bargaining power and employment protection are higher than that of non-regular workers, our results are consistent with the economic theories behind the wage curve.

However, the wage-unemployment relationship is reversed if the share of non-regular workers exceeds approximately 30\%. Therefore, the Japanese wage curve does not hold for the group with a higher degree of duality. A possible explanation for this result is that labor mobility of non-regular workers is higher than that of regular workers. For example, $17.1 \%$ of non-regular workers have changed their jobs since 2007 on annual average, compared to only $7.2 \%$ of regular workers. ${ }^{12}$ Since the wage curve is derived from theories that do not give weight to labor mobility (Shilov and Möller, 2009), this regime may be explained by the theory of compensating differentials (Harris and Todaro, 1970), which explicitly incorporates labor mobility and leads to a positive wage-unemployment relationship. ${ }^{13}$

It is also important to note that non-regular workers in Japan have little chance of achieving regular status, since there is a high degree of employment protection for regular workers (Jones and Urasawa, 2011). OECD (2013) pointed out that only about 10\% of Japanese non-regular workers become regular workers. This fact is consistent with the insider-outsider theory of the labor market. Almost all non-regular workers have fixed-term contracts, and firms hire these workers as a buffer to protect regular workers from dismissal (Jones and Urasawa, 2011). Therefore, non-regular workers are forced to change their jobs more frequently. For this reason, the theory of compensating differentials seems to provide an explanation for the regime with a higher degree of duality.

Finally, we discuss a further implication of the estimation results of Eq. 1. The results may be used in assessing the effects of economic policies that aim to reduce labor market duality

12 Employment Status Survey 2012.
13 For further details, see Blanchflower and Oswald (1994). 
in Japan. Given that problems such as lower wages and employment instability for non-regular workers increase their labor mobility and, consequently, lead to the positive wage-unemployment relationship for the group with a higher degree of duality, the impact of labor market duality can be checked by estimating the unemployment elasticity of wages for the group. The sign and significance of the elasticity - and probably the threshold effect reported in this paper-will be affected by improvement of labor market duality in Japan.

Acknowledgements. I would like to thank Hideyuki Adachi, Yasuyuki Osumi, Tamotsu Nakamura, Takashi Arai, Yasutaka Tsunehiro, Shin Imoto, and seminar participants at the University of Hyogo and Onomichi City University for their helpful comments. Furthermore, this paper owes much to the comments and suggestions of the three anonymous referees. I am solely responsible for any errors.

\section{References}

Aixalá, J. and Pelet, C. (2010) Wage curve versus Phillips curve: a microeconomic estimation for the Spanish case, Análisis Económico, 58, 61-75.

Baltagi, B.H., Başkaya, Y.S. and Hülagü, T. (2013) How different are the wage curves for formal and informal workers? Evidence from Turkey, Papers in Regional Science, 92, 271-283.

Baltagi, B.H., Blien U. and Wolf, K. (2009) New evidence on the dynamic wage curve for Western Germany: 1980-2004, Labour Economics, 16, 47-51.

Baltagi, B.H., Blien U. and Wolf, K. (2012) A dynamic spatial panel data approach to the German wage curve, Economic Modelling, 29, 12-21.

Berg, J. and Contreras, D. (2004) Political-economic regime and the wage curve: Evidence from Chile, 1957-96, International Review of Applied Economics, 18, 151-165.

Blanchflower, D.G. and Oswald, A.J. (1994) The Wage Curve, MIT Press: Cambridge, MA.

Blanchflower, D.G. and Oswald, A.J. (2005) The Wage Curve Reloaded, NBER Working Paper 11338, National Bureau of Economic Research.

Deller, S. (2011) Spatial heterogeneity in the wage curve, Economics Letters, 113, 231-233.

Jones, R.S. and Urasawa, S. (2011) Labour market reforms in Japan to improve growth and equity. OECD Economics Department Working Paper 889, OECD Publishing: Paris.

Hansen, B.E. (1999) Threshold effects in non-dynamic panels: estimation, testing, and inference, Journal of Econometrics, 93, 345-368.

Hansen, B.E. (2000) Sample splitting and threshold estimation, Econometrica, 68, 575-603.

Harris, J.R. and Todaro, M.P. (1970) Migration, unemployment and development: a twosector analysis, American Economic Review, 60, 126-142.

OECD (2013) OECD Economic Survey of Japan, OECD Publishing: Paris.

Ramos, R., Duque, J.C. and Surinach, J. (2010) Is the wage curve formal or informal? Evidence for Colombia, Economics Letters, 109, 63-65.

Shilov, A. and Möller, J. (2009) The wage curve in Russia 1995-2005, Economics Letters, 102, 90-92. 